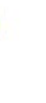

\title{
PREDICTORS OF COUNTERPRODUCTIVE WORKPLACE BEHAVIOR OF NURSES
}

Johnny J. Yao Jr.

Cebu Normal University, Cebu City, Philippines

Correspondence: johnnyyaoj@gmail.com

\begin{abstract}
Disruptive actions in healthcare settings can cause errors, poor client satisfaction, employee turnover, and bigger hospital expenses. This research investigated the determinants of counterproductive work behavior (CWB) such as work-related proactive coping, autonomy, interpersonal conflict, organizational constraints of hospital nurses in a tertiary hospital in large metropolitan city in the Philippines. A descriptive correlational design was utilized in the study. Nurses from the different clinical areas of the hospital were chosen as respondents for this study. Proactive coping received the strongest weight in the model followed by autonomy and organizational constraints; interpersonal conflicts received the lowest of the four weights. Based on the results of the study, the researcher can conclude that work-related proactive coping, autonomy, interpersonal conflicts, and organizational constraints are determinants of counterproductive work behaviors of hospital nurses. Health care managers should formulate customized programs and strategies that can improve employee performance and coping to reduce counterproductive work behaviors. Lastly, further studies would be conducted on other variables that can predict and mediate with counterproductive work behaviors.
\end{abstract}

\section{KEYWORDS}

counterproductive behavior; disruptive behavior; proactive coping; multiple regression; healthcare management

\section{INTRODUCTION}

Every day when workers do not go to work, come late, take money and items, procrastinate on company time, and disrupt the place of work, they are wasting billions of dollars of profits and inventory each year. [1] Collectively all of these are called counterproductive work behavior (CWB) which consists of acts that harm or intend to harm organizations and their stakeholders. [2] Disruptive actions in healthcare settings can cause errors, poor client satisfaction, employee turnover, and increased hospital expenses. [3] Subsequently the major providers in health care are nurses and their roles are also increasing which includes quality improvement activities. [4] It is recognized that no other healthcare professional has such a varied and extensive role. [5] With this in mind, it is important for researchers and managers to focus their attention on them and their impact on health care. Incidentally, nurses' behavior that is detrimental to the organization's effectiveness may lead to low quality patient care and must be dealt with immediately. Healthcare managers must recognize the precursors of such negative actions to decrease its occurrence. 
Researchers have stated that employees who experienced job related stressors were more likely to engage in counterproductive work behavior. [6] These would include lack of control, organizational constraints, workload and interpersonal conflict. It is also important to note that while these may be antecedents to such a behavior, presence of these stressors does not guarantee such behaviors. It is now important to know if there is another factor that will affect the behavior. Knowing if positive coping strategies will also have an impact on counterproductive work behavior is key, since stressors are affected by appraisal and coping behaviors of an individual. [7]

This study aimed to determine whether work related proactive coping, autonomy, interpersonal conflicts, and organizational constraints predicted counterproductive work behavior of nurses in the hospital.

\section{METHODS}

This study utilized a descriptive correlational design. The study was conducted in one of the tertiary hospitals in a large metropolitan city in the Philippines. It is a 200-bed capacity hospital that serves a minimum of 8,000 patients annually. The study was conducted in the various clinical units of the hospital particularly those from the operating room, delivery room, nursery, medical surgical wards, pediatric wards, obstetrics-gynecology (OB) wards, emergency room, and the intensive care unit. The respondents of the study were the nurses of the various clinical units of the hospital. All of the nurses in the various areas were considered to be included in the study. The nurses must be currently employed in the hospital regardless of employee status (i.e. regular, probationary, trainee). Eligible respondents were consecutively asked to participate in the study over a 1 week period. The total number of respondents who participated in the study was seventy-seven. The mean age of the respondents who participated in the study is 24.86 years old and the mean length of work is 2.75 years. Majority $(72.7 \%)$ of the respondents are female, have regular employment status (68.8\%), and have bachelor's degree in nursing (89.6\%).

The study utilized five standardized questionnaires to measure the variables under investigation. The first part of the questionnaire assessed the demographic data of the respondents which includes: age, gender, employment status, educational attainment, and length of employment. The first instrument is the Proactive Coping
Subscale, which is one of the subscales in the Proactive Coping Inventory. The instrument consists of 14 items that combines autonomous goal setting with self-regulatory goal attainment cognitions and behavior. Individuals scoring high on the Proactive Coping subscale are seen as having beliefs that are rich in potential for change particularly in ways that would result in improvement of oneself and one's environment. The scale has high internal consistency with a Cronbach's alpha of .80- .85 .

The second instrument to measure perceived control is the Factual Autonomy Scale (FAS) which was designed to minimize subjectivity in the assessment of workplace autonomy by using items that ask about factual information rather than general judgments. The scale consists of 10 items, with 7 following the question "In your present job, how often do you have to ask permission", and 3 following the question "How often do the following events occur in your present job. Internal consistency reliability estimates (coefficient alpha) are available from 3 samples: University support personnel (alpha $=.81$ incumbents; .82 supervisors); Combination of university support personnel and other private sector employees (alpha $=.83$ incumbents; .85 coworkers; Employed university students (alpha $=.87$ ).

The items of the FAS are statements asking how often someone else has control. Response choices ask how often each item occurs, where 1 = the least frequent response (Never) and 5 = the most frequent response (Extremely often or always, or Every day). The items should be reverse scored. This can be done easily by subtracting responses to each item from 6, and then summing the items after this reversal. Thus, a score of 5 becomes a 1, a score of 4 becomes a 2, 3 remains 3, 4 becomes 2, and 5 becomes 1 . This will result in high scores representing high control rather than low control.

The third instrument is the Interpersonal Conflict at Work Scale (ICAWS). Interpersonal conflict in the workplace has been shown to be one of the most frequently reported job stressors. The ICAWS is a four item, summated rating scale designed to assess this construct. Its items ask about how well the respondent gets along with others at work, specifically getting into arguments with others and how often others act nasty to the respondent. Five response choices are given, ranging from less than once per month or never, coded 1, to several times per day, coded 5. High scores represent frequent conflicts with others, with a 
possible range from 4 to 20. Internal consistency reliability (coefficient alpha) was to average .74 across 13 studies. [8]

The fourth instrument is the Organizational Constraints Scale (OCS). Organizational constraints are situations or things that interfere with task performance at work. One item assesses each of the 11 constraint areas, and all items are summed into a total score. Respondents are asked to indicate how often it is difficult or impossible to do his or her job because of each item. High scores represent high levels of constraints, with a possible range of scores from 11 to 55 .

The fifth instrument is the Counterproductive Work Behavior Checklist (CWB-C) which consists of acts that harm or are intended to harm organizations. They include acts directed toward both organizations and individuals, including aggression (physical and verbal), sabotage, theft, and withdrawal. The Counterproductive Work Behavior Checklist (CWB-C) comes in two versions. The full 45-item was designed to be scored as either overall CWB (all items), or as two subscales (43 items) that are classified into CWB directed toward the organization versus people. Cronbach's alpha ranges from .55 - .90.
Upon approval, the researcher started gathering the data from the different areas of the hospital. Permission from the respective unit managers was secured to distribute the questionnaires to the nurses. The researcher used structured questionnaires in gathering the data. Together with the questionnaires, a written explanation was attached and it was accompanied by a verbal explanation to explain to all the participants regarding the goals and the objectives of the study. The nurses were informed regarding the use of the questionnaires in the study. The researcher reassured the nurses that a high degree of privacy and anonymity will be maintained. All questionnaires were kept in a long-sized expandable envelope, which were accessible only by the researcher.

Descriptive statistics were used to summarize and organize the data collected such as percentages and means. Multiple regression was used to know the relationship of the different variables and were used to be able to make predictions regarding the variables. All data were analyzed and set at a 0.05 level of significance using the SPSS version 17 statistical software.

\section{RESULTS}

TABLE 1. PREDICTORS OF COUNTERPRODUCTIVE WORKPLACE BEHAVIOR

\begin{tabular}{|c|c|c|c|c|c|}
\hline VARIABLE & $\mathbf{R}^{2}$ & $\mathbf{F}$ & B & SE (B) & B \\
\hline & .60 & $26.7^{* * *}$ & & & \\
\hline Proactive coping & & & $-.485^{* * *}$ & .287 & $-.677^{* * *}$ \\
\hline Autonomy & & & $-.227^{* * *}$ & .066 & $-.642 * * *$ \\
\hline Interpersonal Conflict & & & $.098^{*}$ & .029 & $.310 *$ \\
\hline Organizational Constraints & & & $-.122^{* *}$ & .038 & $-.389 * *$ \\
\hline
\end{tabular}

Note. $n=77 . B=$ unstandardized beta. $S E=$ standard error. $\beta=$ standardized beta. ${ }^{*} p<.05 .{ }^{* *} p<.01 .{ }^{* * *} p<.001$.

Table 1 shows the prediction model was statistically significant, $F(4,72)=26.7, p<.000$ and shows that the regression model has an $\mathrm{R}^{2}$ of .60 . This means that about $60 \%$ of the variability of the dependent variable, which is CWB, is predicted by the independent variables included in the study. The remaining $40 \%$ of the variability in the dependent variable is still unaccounted for and may be caused by other variables or external factors that were not included in the study.

Proactive coping, autonomy, interpersonal conflicts, and organizational constraints were used in the regression analysis to predict CWB. Table 1 presents the different predictors of CWB used in the study. The unstandardized 
and standardized regression coefficients of the predictors are also shown in Table 1.

All of the predictors have probability values of less than 0.05 which is the level of significance. This indicates that the independent variables - proactive coping, autonomy, interpersonal conflicts, and organizational constraints have significant relationships to the dependent variable, CWB. Proactive coping, autonomy, and organizational constraints have negative coefficients which means that for every one-point increase in these variables there will be a corresponding decrease equivalent to the value of its beta coefficient in the level of CWB. Interpersonal conflict has a positive coefficient which means that an increase or decrease of its value will subsequently increase or decrease the level of CWB, respectively. Proactive coping received the strongest weight in the model followed by autonomy and organizational constraints; interpersonal conflicts received the lowest of the four weights.

\section{DISCUSSION}

Results from the multiple regression support the theory of Greenglass' [7] which states that proactive coping can directly reduce negative outcomes by altering how the stressor is interpreted. In the Stressor Emotion Model, perception of a stressor is important in determining if it induces a negative emotion which leads to CWB. People with proactive coping perceive difficult situations as challenges. Coping becomes goal management instead of risk management. Individuals initiate a constructive path of action and create opportunities for growth. It is because of this that the appraisal of being threatening is transformed into being challenging which will result in mastery and personal growth if overcome. Proactive coping strategies and behaviors at work involving mastery or problem-solving are associated with more positive outcomes and decreased distress. This in turn will decrease counterproductive workplace behaviors.

The results also support the study of Greenglass \& Fiksenbaum [9] which suggests that proactive coping is a self-regulatory coping strategy that is associated with higher levels of well-being, lower levels of depression, and better psychological functioning. These studies found out that higher levels of proactive coping had lower burnout and anger scores, a greater sense of professional efficacy, perceive more fair treatment at work and experience greater life satisfaction.
Several studies in Canada, Poland, and Germany have found that proactive coping is positively correlated with perceived self-efficacy and negatively with job burnout in different professions. [12] Findings further indicate that proactive coping is significantly associated with lower burnout and higher professional efficacy in employed Canadian adults, $[7,11]$ and with lower threat and less loss appraisals in German teachers. [10]

In a cross-sectional study of community-dwelling seniors, proactive coping was associated with less functional disability, less depression, and greater perceived social support. [11] In another cross-sectional study with Canadian-Turkish immigrants, proactive coping was associated with greater optimism, greater life satisfaction, and less depression; [12] regression analyses showed that proactive coping accounted for a significant degree of unique variance in depression scores, over and above the variance attributable to trait optimism. [12]

The results show that autonomy is also a significant predictor of CWB. This supports the stressor emotion model of CWB by Fox and Spector [13] which states that perceived control is an important moderator of both perceptions and behavioral reactions. Controllable situations are less likely to be perceived as stressors and therefore will be less likely to result in negative emotions [8]. Also, Allen and Greenberger [14] suggested that perceptions of control are an important determinant of counterproductive work behavior, as non-constructive behavioral responses are more likely when a person perceives low control of the situation. Stressors that people perceive to have little control over will have a greater negative affect on health when compared to those that people perceive as having more control over. Appraisal of a stressful situation can affect the perception of control over the stressor, thus becoming an important part of managing stress efficiently.

For instance, the study of Fox et al. [15] found out that autonomy correlated significantly with organizational CWB. In a study of nurses, those who perceived a sense of control over stressful situations experienced fewer negative effects.[16] Researchers have also found that participants who reported a higher sense of control showed better adjustment after trauma. [17]

The result also shows that interpersonal conflict is a significant predictor of CWB. This supports the Stressor Emotion Model of CWB which states that stressful job 
conditions such as having personal conflict at work can induce negative emotion which will lead to CWB. Interpersonal conflict with the supervisor can lead to counterproductive work behaviors such as defiance, undermining, and colluding with coworkers to engage in deviant behavior. Interpersonal conflict with peers can lead to counterproductive work behaviors such as harassment, bullying, and physical altercations. [18] Several studies which included interpersonal conflict also found significant correlations with CWB. $[13,15,19,20]$ The efforts to decrease the incidence of these conflicts can also decrease the incidence of CWBs.

Lastly, organizational constraint is also a significant predictor of CWB. However, it has negative relationship with CWB which is contrary to the theory that states that stressors will cause negative emotions leading to CWB. Spector [21] showed that frustration at work related to selfreported CWB. A self-report measure of constraints correlated significantly with self-reports of several categories of CWB, including aggression, hostility and complaining, sabotage and withdrawal, as well as with feelings of frustration which showed similar relations with CWB. The study of Chen and Spector [22] included measures of role ambiguity, role conflict, interpersonal conflict, and workload along with organizational constraints. All five correlated significantly with hostility, and all but workload correlated significantly with aggression and sabotage.

It may be surmised that one likely reason that organizational constraint is negatively related is that workers will less likely engage in negative behaviors that might lead to more stressful situations. If a worker engages in CWB because of stressors such as organizational constraints, the worker might get punished or disciplined. This makes an already stressful work environment a lot worse. The employee will not think of doing anything that might make the situation much worse than it already is. It is also important to note that the organizational constraints that were perceived in the study are those that are difficult to change by the employee alone such as lack of equipment. This might suggest that the type of constraint may also affect whether or not CWB is exhibited. It might also be futile to engage in CWB if it does not change or eliminate the cause of the stressor. So, the nature of the constraint as being less likely to be changed compared to other stressors such as interpersonal constraints may be a factor of this finding.
Another reason might be due to the mediating effect of proactive coping in the appraisal of the stressor. This is consistent with the theory of Greenglass which states that in proactive coping, people have a vision and see risks, demands, and opportunities in the far future, but they do not appraise these as threats, harm, or loss. Rather, they perceive difficult situations as challenges. Proactive coping will mediate the perception of the stressors positively, and decrease the negative emotions associated with the stressor. This in turn will affect the manifestation of counterproductive work behaviors. [9] This means that even with actual work stressors, the nurses may not appraise them as threatening and instead look pass it and see the opportunity for growth if these obstacles are overcome.

\section{CONCLUSION}

In summary, the results suggest that having high levels of proactive coping will mostly likely decrease the incidence of the nurses to engage in CWB. It also noteworthy to state that the presence of interpersonal conflicts will likely increase the incidence of CWB. Moreover, having high autonomy or control in the workplace will decrease the incidence of nurses to engage in CWB. Surprisingly, organizational constraints will decrease the incidence of CWB. This may be a purposeful decision of the nurses to not let a bad situation get worse. Proactive coping may also mediate their perception regarding this stressor and in turn their intentions to resort to CWBs.

\section{IMPLICATIONS}

All of these results imply that the presence of stressors, and individual characteristics such as coping styles and percieved autonomy of employees should be considered in the scheme and policies of organizations. This would mean that organizations should be implementing appropriate management practices that enhance employee performance and wellbeing, building a healthy work environment and organizational effectiveness. Employee performance and welfare can be achieved by reducing unnecessary stress and developing proactive coping styles. Ignoring such matters will likely have harmful effects, not only by increasing the chance of CWBs but also by decreasing performance and job satisfaction. 


\section{References}

1. Performance Technology Group. Get the Counterproductive Behavior Index ${ }^{\mathrm{TM}}$ to stop bad hires. 2010.

http://www.hrdptg.com/storage/cbitechnicalmanual. pdf

2. Fox, S. \& Spector, P.E. Counterproductive work behavior: Investigations of actors and targets. Washington, DC: APA Press; 2005

3. Joint Commission. Behaviors that undermine a culture of safety. 2008.

http://www.jointcommission.org/assets/1/18/SEA_40.P DF

4. Draper, D.A., Felland, L.E., Liebhaber, A., Melichar, L. (2008). The role of nurses in hospital quality improvement.

http://www.hschange.com/CONTENT/972/

5. Mcgill University. Importance of nursing. 2011. http://www.mcgill.ca/nursing/today/importance

6. Spector, P.E., Fox, S., Domagalski, T. Emotions, violence, and counterproductive work behavior. 2005. http://www.corwin.com/upmdata/8744_KellowayCh3.pdf

7. Greenglass, E. Chapter 3. Proactive coping. In E. Frydenberg (Ed.), Beyond coping: Meeting goals, vision, and challenges (pp. 37-62). London: Oxford University Press; 2002

8. Spector, P.E. A control model of the job stress process. In C. L. Cooper (Ed.). Theories of Organizational Stress (pp. 153-169). London: Oxford University Press; 1998

9. Greenglass, E.R. and Fiksenbaum, L. Proactive coping, positive affect, and well-being: Testing for mediation using path analysis. European Psychologist 2009, 14(1), 29-39. doi: 10.1027/1016-9040.14.1.29

10. Schwarzer, R., \& Taubert, S. Tenacious goal pursuits and striving toward personal growth: Proactive coping. In E. Frydenberg (Ed.), Beyond coping: Meeting goals, visions and challenges (pp. 19-35). London: Oxford University Press; 2002

11. Greenglass, E., Fiksenbaum, L., Eaton, J. The relationship between coping, social support, functional disability and depression in the elderly. Anxiety, Stress and Coping 2006, 19(1): 15-31.

12. Uskul, A.K., \& Greenglass, E.R. Psychological well-being in a Turkish-Canadian sample. Anxiety, Stress, and Coping: An International Journal 2005, 18, 269-278.
13. Fox, S., \& Spector, P.E. A model of work frustrationaggression. Journal of Organizational Behavior 1999, 20, 915-931.

14. Allen, V.L., \& Greenberger, D.B. Destruction and perceived control. In A. Baum \& J. E. Singer (Eds.). Applications of personal control (pp. 85-109). Hillsdale, NJ: Lawrence Erlbaum; 1980

15. Fox, S., Spector, P.E., \& Miles, D. Counterproductive work behavior (CWB) in response to job stressors and organizational justice: Some mediator and moderator tests for autonomy and emotions. Journal of Vocational Behavior 2001, 59, 291-309. doi:10.1006/jvbe.2001.1803

16. Boey, K.W. Distressed and stress resistant nurses. Issues in Mental Health Nursing 1999, 20, 33-54.

17. Frazier, P., Steward, J., \& Mortensen, H. Perceived control and adjustment to trauma: A comparison across events. Journal of Social \& Clinical Psychology 2004, 23, 303-324.

18. Sackett, P.R. The structure of counterproductive work behaviors: Dimensionality and relationships with facets of job performance. International Journal of Selection and Assessment 2002, 10, 5-11.

19. Miles, D.E., Borman, W.E., Spector, P.E., \& Fox, S. Building an integrative model of extra role work behaviors: A comparison of counterproductive work behavior with organizational citizenship behavior. International Journal of Selection and Assessment 2002, 10, 51-57.

20. Penney, L.M. \& Spector P.E. Workplace incivility and counterproductive workplace behavior. Paper presented at the meeting of the Society for Industrial and Organizational Psychology, Orlando; 2003

21. Spector, P.E. Relationships of organizational frustration with reported behavioral reactions of employees. Journal of Applied Psychology 1975, 60, 635-637.

22. Chen, P.Y., \& Spector, P.E. Relationships of work stressors with aggression, withdrawal, theft and substance use: An exploratory study. Journal of Occupational and Organizational Psychology 1992, 65, 177-184. 